Gut, 1970, 11, 947-954

\title{
Further studies on the perfusion method for measuring intestinal absorption in man: The effects of a proximal occlusive balloon and a mixing segment
}

\author{
G. E. SLADEN AND A. M. DAWSON \\ From the Department of Gastroenterology, St Bartholomew's Hospital, London, EC1
}

SUMMARY The reliability and accuracy of the two-lumen tube perfusion method for measuring intestinal absorption in man has been assessed by the use of a proximal occlusive balloon in nine normal volunteers.

Luminal occlusion significantly reduced the variability of individual glucose and water absorption rates, and reduced the variability of triplicate marker concentrations within individual studies. Mean absorption rates of glucose, water, sodium, and chloride were not significantly affected by luminal occlusion. Absorption rates obtained with the triple-lumen tube method were rather more variable both within and between individuals, but a statistical comparison of the accuracy of the two methods could not be made.

These results are discussed in relation to the contribution of endogenous gut secretion and proximal reflux of infused fluid to the variability of absorption rates obtained by the perfusion technique.

Perfusion techniques are now widely used in the investigation of various aspects of human intestinal and colonic function (reviewed by Sladen, 1969) but there is disagreement about methodological details and the indications for the different available techniques. A major source of debate is the importance of excluding contaminating upper gastrointestinal secretions from above. In a previous study (Sladen and Dawson, 1968) we suggested that the magnitude and importance of such contamination in absorption studies in normal subjects had been exaggerated by others. However, Fordtran (1969) and Soergel (1969) have criticized this interpretation, mainly on the grounds that we failed to take into account the effect of proximal reflux of infused fluids, exposing a greater surface area for absorption.

In the present study a more direct attempt has been made to quantitate the effects of contamination and reflux, by using a proximal occlusive balloon and comparing the effects of inflation and deflation of the balloon on segmental absorption rates. A slightly modified version of the technique Received for publication 6 March 1970. described by Phillips and Summerskill (1966) has been used. Effects on glucose and water absorption have been studied in detail because, whereas glucose absorption rates are affected only by reflux, water absorption rates are affected by both reflux and contamination with opposite results.

\section{Methods}

The perfusion system used is shown in Figure 1. Double-lumen tubing (Portex polyvinyl tubing MLT/B; external diameter $4.2 \mathrm{~mm}$ ) was attached to a mercury bag with the distal interposition of single-lumen tubing (transparent vinyl NT/6; external diameter $4 \cdot 13 \mathrm{~mm}$ ). It was found that this single-lumen component facilitated the distal recovery of intestinal contents. The inlet and distal collection orifices were $30 \mathrm{~cm}$ apart. Fine tubing (Portex PP/25; external diameter $0.80 \mathrm{~mm}$ ) was threaded through the inlet lumen of the double-lumen assembly and led into the balloon as shown. The balloons (obtained from the 

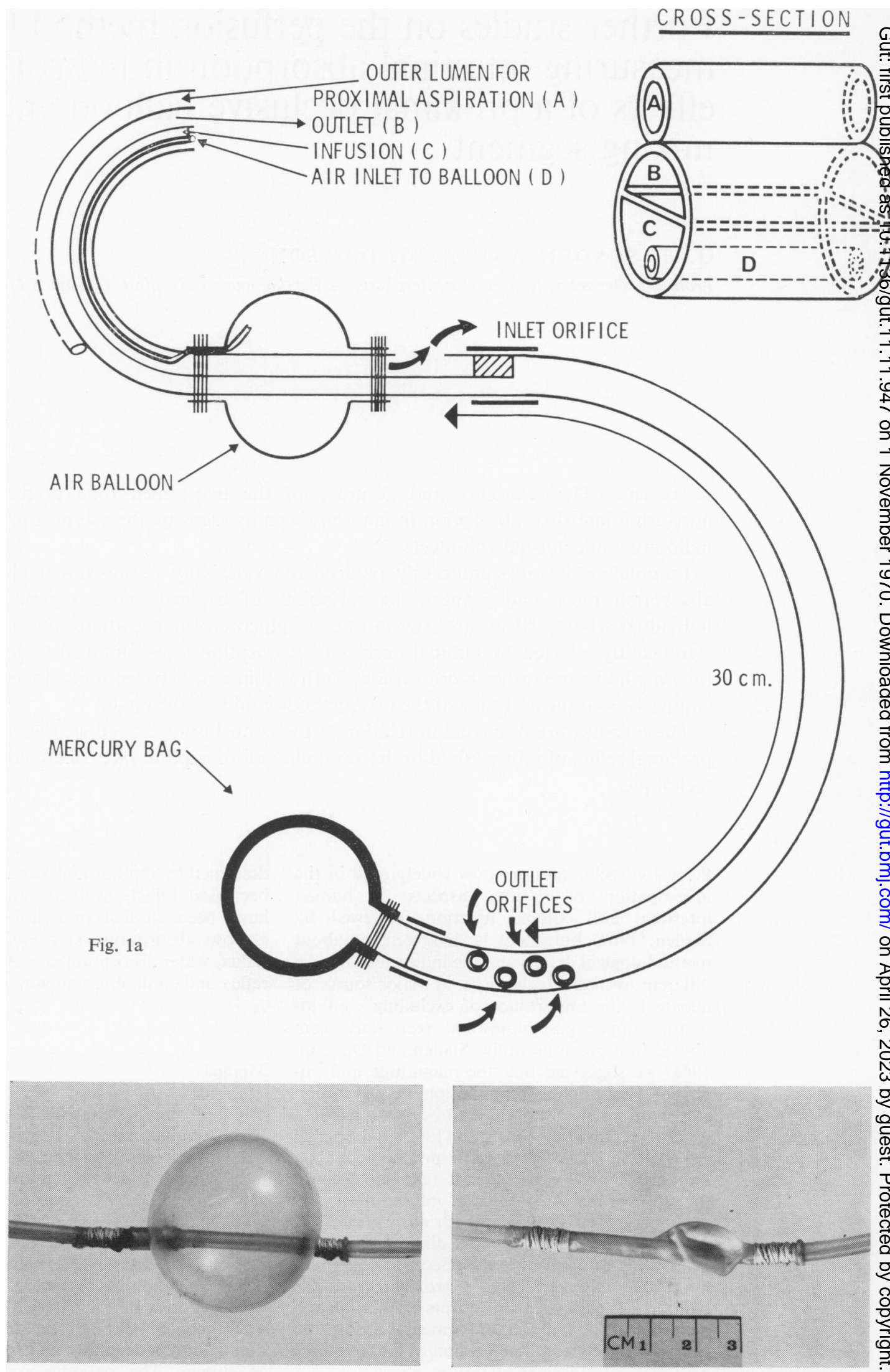

Fig. 1b

Fig. 1c

Fig. 1 Diagram of the tube used in the present study (a); Photographs of the inflated (b) and deflated (c) balloon. 
London Rubber Company; reference number $18 / 26 / 37$ ) were secured by linen thread to the two-lumen assembly. An outer proximal aspiration tube (Portex radioopaque tubing $\mathrm{R} / 3 \mathrm{SH} 85$; external diameter $2.5 \mathrm{~mm}$ ) was attached and several orifices were cut into its distal end, which lay $4-5 \mathrm{~cm}$ proximal to the balloon. All seals were made with vinyl cement ${ }^{1}$. The balloons were inflated with $30-50 \mathrm{ml}$ of air and would remain inflated for periods of at least one hour. Figure 1c shows that the collapsed balloon would occupy very little space within the intestinal lumen and should not prevent either contamination or reflux.

Nine normal male volunteers (aged 21-33 years) were studied. After an overnight fast the tube was swallowed at $8.30 \mathrm{am}$. Within one and a half to five hours, the tube reached the ideal position with the balloon distal to the duodenojejunal flexure. The passage of the tube was radiologically assessed.

Solutions were pumped at a constant rate $(20$ $\mathrm{ml}$ per minute) through the infusion orifice using a Watson-Marlow pump ${ }^{2}$ from polythene bottles placed in a water bath at $37^{\circ} \mathrm{C}$. Following an equilibration period of 30 minutes, three timed 10-minute samples were obtained by siphonage from the distal orifices. Aliquots from the samples were frozen and stored for analysis. Each subject was perfused at least once with the balloon inflated and once with the balloon deflated for an hour each time. The order of the perfusions was alternated. In all subjects it was possible to maintain 30-50 ml air in the balloons for an hour without undue distress, although this varied from subject to subject. In only one subject (excluded from the series) was distress sufficient to preclude the use of the balloon. The efficacy of the balloon was tested by the injection of boluses of $5 \mathrm{ml}$ phenol red (phenolsulphthalein $5 \mathrm{mg} / 100 \mathrm{ml}$ ) down the outer lumen (lumen $A$ in Fig. 1a). After five minutes the proximal contents were aspirated and much of the phenol red was recovered. Distal samples were tested for phenol red at the bedside by the addition of $\mathrm{N} / 10 \mathrm{NaOH}$. Provided distal siphonage was adequate, it was always possible to detect leaks and to correct these by re-inflation of the balloon. The vast majority of the samples subsequently analysed contained no detectable phenol red or bile and the remainder contained trace amounts. After the proximal aspiration of phenol red a further fresh bolus was injected and this was repeated at intervals of approximately 10 minutes during the hour's perfusion.

A solution of the following composition was used throughout: glucose $56 \mathrm{mM}$; $\mathrm{NaCl} 120 \mathrm{mM}$; and PEG (the non-absorbed marker polyethylene glycol) $2.5 \mathrm{~g} / \mathrm{l}$ : tonicity $280 \mathrm{mOsm} / \mathrm{kg}$. The infused solution and distal samples were analysed for PEG using the method of Hyden (1955); for

${ }^{1}$ This together with all the tubing was obtained from Portland Plastics, Hythe, Kent.

${ }^{2}$ H.F. inducer Watson-Marlow Ltd, Marlow, Bucks. glucose using the glucose-oxidase method (Huggett and Nixon, 1957); for sodium using standard flame photometry (EEL photometer, Evans Electroselenium Ltd, Halstead, Essex); and for chloride using coulometric titration (EEL chloride meter). The osmolality was measured with an Advanced osmometer ${ }^{3}$.

Absorption rates of glucose, water, sodium, and chloride were calculated using standard formulae (Sladen and Dawson, 1968), individual absorption rates representing the arithmetic mean of triplicate observations.

Some of the results given refer to earlier work using a triple-lumen tube incorporating a mixing segment (Cooper, Levitan, Fordtran, and Ingelfinger, 1966). The methods used and the main results obtained have already been reported in full (Sladen and Dawson, 1968 and 1969a). Some aspects of these results, not previously reported, are presented here for comparative purposes only. Similarly reference is made to previous results obtained with the simple, unmodified doublelumen tube (Sladen and Dawson, 1969b) again for comparative purposes.

\section{Results}

Individual rates of water, glucose, sodium, and chloride absorption are shown in Figure 2. Each individual is represented by linked points showing absorption rates with and without luminal occlusion. The mean values and various statistical derivations are shown in the first two columns of Table I.

These mean values are compared with those obtained previously using the simple doublelumen tube without balloon (Table I, column 3, from the study reported by Sladen and Dawson, 1969a) and using a triple-lumen tube incorporating a mixing segment (Table I, column 4, from studies reported by Sladen and Dawson, 1968 and 1969b). Columns 1 and 3 of Table I are directly comparable because infusion rates, segment lengths, and luminal solute concentrations are identical. However, the results shown in column 4 cannot be compared statistically, because the inflow rates and solute composition of fluid entering the study segment are different, as indicated in the legend, and both these factors may affect segmental absorption rates.

The effect of luminal occlusion on the variability of triplicate observations within individuals has also been determined in the present study in order to assess the effects of reflux and contamination on the achievement of a steady state. The range of triplicate observations in each individual has been expressed as a percentage of the mean, and the results relating to PEG concentrations and glucose and sodium absorption

sAdvanced Instruments, Inc., Newton Highlands, Massachusetts, USA. 


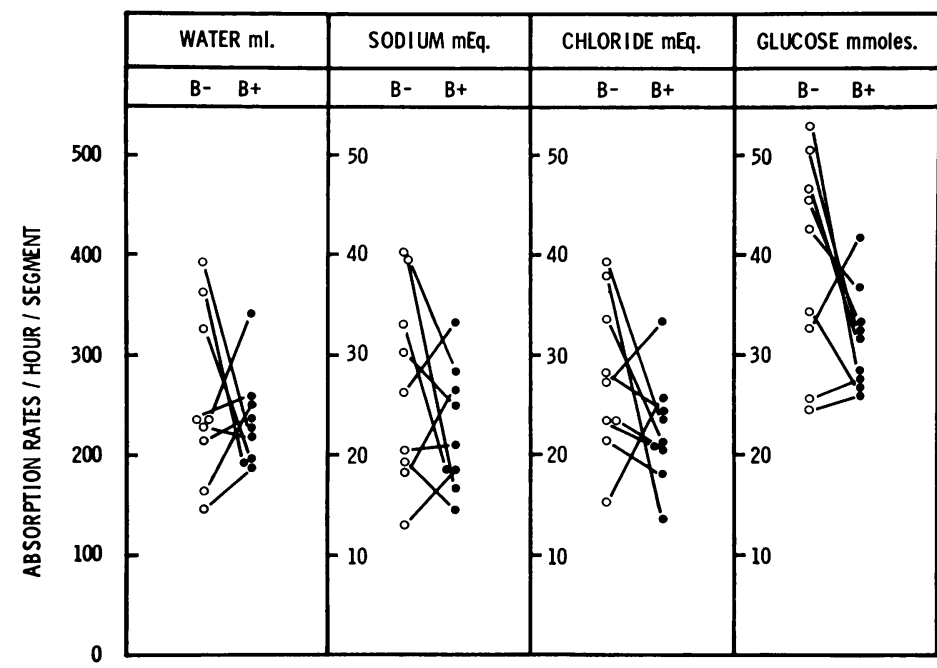

Fig. 2 Individual water and solute absorption rates in units per hour. The infusion rate is $20 \mathrm{ml}$ per minute and the segment length is $30 \mathrm{~cm}$. (B- = balloon deflated, $\mathrm{B}+=$ balloon inflated $)$. Paired observations in individual studies are indicated. All solutions contained $56 \mathrm{mM}$ glucose and $120 \mathrm{mM}$ sodium chloride.

\begin{tabular}{|c|c|c|c|c|}
\hline & \multicolumn{2}{|c|}{ Present Series } & \multicolumn{2}{|c|}{ Previous Series } \\
\hline & $\begin{array}{l}\text { Balloon } \\
\text { Deflated }^{2}\end{array}$ & $\begin{array}{l}\text { Balloon } \\
\text { Inflated }^{2}\end{array}$ & $\begin{array}{l}\text { Two-lumen } \\
\text { Tube }^{2}\end{array}$ & $\begin{array}{l}\text { Three- } \\
\text { lumen Tube }\end{array}$ \\
\hline \multicolumn{5}{|c|}{ Absorption of water $(\mathrm{ml})$} \\
\hline Mean & 257 & 237 & 332 & 222 \\
\hline & 9 & 9 & 11 & 11 \\
\hline & $86 \cdot 7$ & $48 \cdot 7$ & 106 & 116 \\
\hline \multicolumn{5}{|l|}{ SE } \\
\hline $\begin{array}{l}\text { Coefficient of } \\
\text { variations }\end{array}$ & 34 & $20 \cdot 5$ & 32 & 52 \\
\hline \multicolumn{5}{|c|}{ Absorption of sodium (m-equiv) } \\
\hline Mean & 26.8 & $22 \cdot 6$ & 30 & 14 \\
\hline $\mathrm{n}$ & 9 & 9 & 11 & 11 \\
\hline SD & 9.9 & $6 \cdot 2$ & $12 \cdot 3$ & $10 \cdot 9$ \\
\hline & $3 \cdot 3$ & $2 \cdot 1$ & 3.7 & $3 \cdot 3$ \\
\hline \multicolumn{5}{|l|}{ Coefficient of } \\
\hline \multicolumn{5}{|c|}{ Absorption of chloride (m-equiv) } \\
\hline Mean & $28 \cdot 7$ & $22 \cdot 5$ & $30 \cdot 4$ & $16 \cdot 1$ \\
\hline n & 9 & 9 & 11 & 11 \\
\hline SD & 8 & 5.6 & $12 \cdot 6$ & $8 \cdot 3$ \\
\hline & $2 \cdot 7$ & 1.9 & 3.8 & $2 \cdot 5$ \\
\hline \multicolumn{4}{|l|}{ Coefficient of } & 46 \\
\hline \multicolumn{5}{|c|}{ Absorption of glucose $(\mathrm{m} \mathrm{mol})$} \\
\hline Mean & $39 \cdot 5$ & $31 \cdot 3$ & 41 & 44 \\
\hline $\mathbf{n}$ & 9 & 9 & 11 & \\
\hline SD & $10 \cdot 3$ & $5 \cdot 6$ & $9 \cdot 3$ & $16 \cdot 3$ \\
\hline \multirow{2}{*}{\multicolumn{5}{|c|}{ Coefficient of }} \\
\hline & & & & \\
\hline & 26 & $17 \cdot 7$ & 23 & 35 \\
\hline
\end{tabular}

Table I A comparison of mean water and solute absorption rates obtained by several perfusion techniques ${ }^{1}$

${ }^{1}$ All absorption rates refer to a segment of jejunum $(30 \mathrm{~cm})$ and are in units/hour.

${ }^{2}$ The infusion rate is $20 \mathrm{ml} / \mathrm{min}$ and the solutions contained $56 \mathrm{mM}$ glucose and $120 \mathrm{mM}$ sodium chloride.

${ }^{3}$ Mean ( \pm ISD) infusion rate is $15.5( \pm 3.2) \mathrm{ml} / \mathrm{min}$, glucose concentration $102( \pm 13) \mathrm{mM}$, and sodium chloride $95( \pm 1 \cdot 8)$ mM.

"Number of individuals in each group.

${ }^{5}$ The standard deviation expressed as a percentage of the mean. rates are shown in Figure 3. As before, the $\Omega$ individuals are represented by two linked points in each column, showing the effect of balloon inflation. For comparison with the triple-lumen mixing segment method a similar analysis of the results obtained in the previous study is incorporated into Figure 3. In view of the expected skew distribution, median values are given at the foot of each column.

Various statistical methods have been used to assess the significance of results relating to data obtained with the two-lumen tube methods. The mean absorption rates in the present series (Table I, columns 1 and 2) are all reduced by occlusion of the lumen. The $t$ test on paired differences shows, however, that none of these differences are statistically significant at the $5 \%$ level, although the difference between mean glucose absorption rates is nearly so $(\mathrm{t}=2 \cdot 24$, $P \geqslant 0.05$ ). The mean absorption rates shown in columns 1 and 3 of Table I, comparing the present results with those obtained in the absence of a balloon, are also not significantly different using Student's $t$ test ( $P>0.05$ in all cases).

The variation of results both between (Fig. 2) and within (Fig. 3) individual subjects has been assessed by an analysis of the variance of all the

\begin{tabular}{|c|c|c|c|c|}
\hline & $\begin{array}{l}\text { Source of } \\
\text { Variation }\end{array}$ & $\begin{array}{l}\text { Degrees } \\
\text { of } \\
\text { Freedom }\end{array}$ & $\begin{array}{l}\text { Sum of } \\
\text { Squares }\end{array}$ & $\begin{array}{l}\text { Mean } \\
\text { Square }\end{array}$ \\
\hline $\begin{array}{l}\text { PEG concentration } \\
\text { Balloon deflated }\end{array}$ & $\begin{array}{l}\text { Between subjects } \\
\text { Within subjects } \\
\text { Total }\end{array}$ & $\begin{array}{r}8 \\
19 \\
27\end{array}$ & $\begin{array}{r}9,064 \\
5,716 \\
14,780\end{array}$ & $\begin{array}{r}1,133 \\
301\end{array}$ \\
\hline Balloon inflated & $\begin{array}{l}\text { Between subjects } \\
\text { Within subjects } \\
\text { Total }\end{array}$ & $\begin{array}{r}8 \\
16 \\
24\end{array}$ & $\begin{array}{r}7,512 \\
693 \\
8,205\end{array}$ & $\begin{array}{r}939 \\
43\end{array}$ \\
\hline $\begin{array}{l}\text { Water absorption } \\
\text { Balloon deflated }\end{array}$ & $\begin{array}{l}\text { Between subjects } \\
\text { Within subjects } \\
\text { Total }\end{array}$ & $\begin{array}{r}8 \\
16 \\
24\end{array}$ & $\begin{array}{r}179,417 \\
57,083 \\
236,500\end{array}$ & $\begin{array}{c}22,427 \\
3,568\end{array}$ \\
\hline Balloon inflated & $\begin{array}{l}\text { Between subjects } \\
\text { Within subjects } \\
\text { Total }\end{array}$ & $\begin{array}{r}8 \\
16 \\
24\end{array}$ & $\begin{array}{l}49,093 \\
14,160 \\
63,253\end{array}$ & $\begin{array}{r}6,137 \\
885\end{array}$ \\
\hline $\begin{array}{l}\text { Sodium absorption } \\
\text { Balloon deflated }\end{array}$ & $\begin{array}{l}\text { Between subjects } \\
\text { Within subjects } \\
\text { Total }\end{array}$ & $\begin{array}{r}8 \\
16 \\
24\end{array}$ & $\begin{array}{r}2,216 \\
212 \\
2,428\end{array}$ & $\begin{array}{l}227 \\
13 \cdot 3\end{array}$ \\
\hline Balloon inflated & $\begin{array}{l}\text { Between subjects } \\
\text { Within subjects } \\
\text { Total }\end{array}$ & $\begin{array}{r}8 \\
18 \\
26\end{array}$ & $\begin{array}{r}924 \\
261 \\
1,185\end{array}$ & $\begin{array}{l}116 \\
14 \cdot 5\end{array}$ \\
\hline $\begin{array}{l}\text { Glucose absorption } \\
\text { Balloon deflated }\end{array}$ & $\begin{array}{l}\text { Between subjects } \\
\text { Within subjects } \\
\text { Total }\end{array}$ & $\begin{array}{r}8 \\
19 \\
27\end{array}$ & $\begin{array}{r}3,180 \\
210 \\
3,390\end{array}$ & $\begin{array}{l}398 \\
11 \cdot 1\end{array}$ \\
\hline Balloon inflated & $\begin{array}{l}\text { Between subjects } \\
\text { Within subjects } \\
\text { Total }\end{array}$ & $\begin{array}{r}8 \\
17 \\
25\end{array}$ & $\begin{array}{r}934 \\
261 \\
1,196\end{array}$ & $\begin{array}{c}116 \\
15 \cdot 4\end{array}$ \\
\hline
\end{tabular}

Table II Analysis of variance of PEG concentration and absorption rates of water, sodium, and glucose to show the effects of luminal occlusion by the proximal balloon ${ }^{1}$

${ }^{1}$ Numbers have been rounded off for clarity (Snedecor and Cochran, 1967).

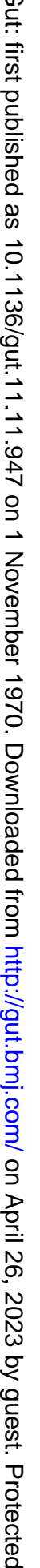


results obtained with the double-lumen tube technique. The analysis of variance relating to the present results is shown in Table II. The following conclusions are derived from the variance ratios (F). The within-individual variances of PEG concentrations and water absorption rates are significantly reduced by luminal occlusion $(F=$ $7.0, \mathrm{P}<0.002$ and $\mathrm{F}=4.03, \mathrm{P}<0.005$ respectively). Within-individual variances of glucose and sodium absorption rates are not significantly affected ( $P>0 \cdot 2$ in each case). Between-individual variances of water and glucose absorption rates are significantly reduced by luminal occlusion $(\mathrm{F}=3.655, \mathrm{P}<0.05$ and $\mathrm{F}=3.44, \mathrm{P}=0.05$ respectively), whereas the other between-individual variances are unaffected $(P>0 \cdot 2)$. Finally analysis of variance of all the results relating to columns 1 and 3 of Table I shows that neither

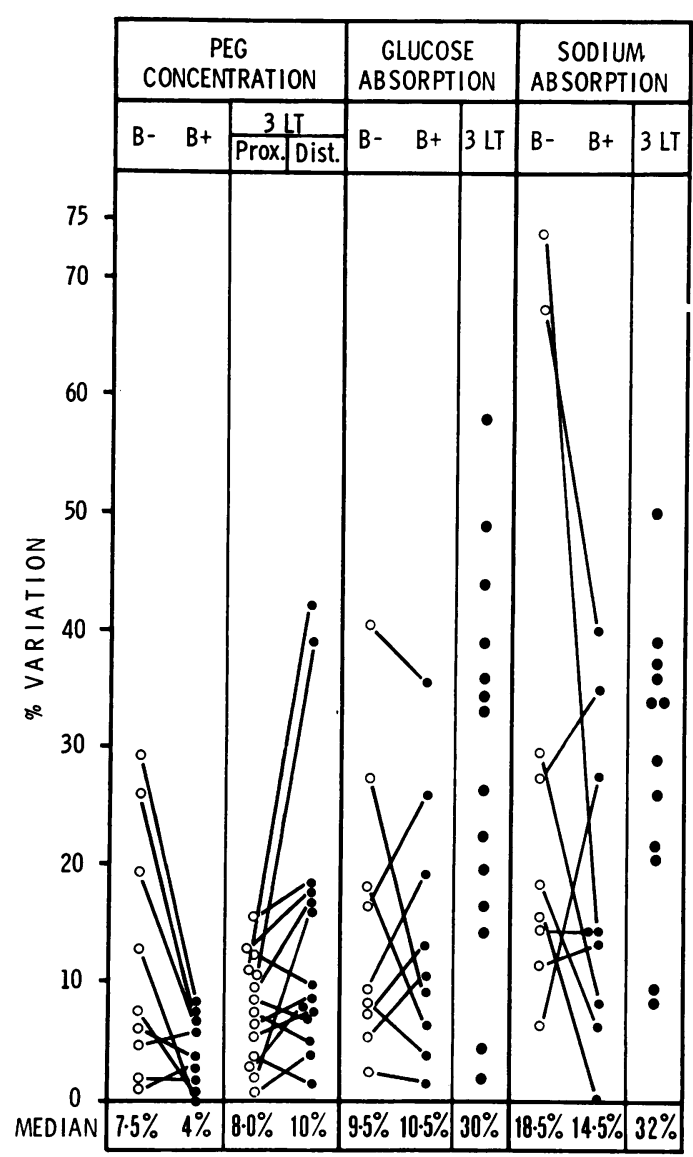

Fig. 3 Intra-individual variation of PEG concentration and glucose and sodium absorption rates in both the present series and in the studies using the triplelumen tube. Each result represents the range of three values expressed as a percentage of the mean. Paired observations within individuals are indicated when appropriate. $(\mathrm{B}-=$ balloon deflated $; \mathrm{B}+=$ balloon inflated; $3 \mathrm{LT}=3$ lumen tube; $\mathrm{PROX}=$ proximal concentration; and DIST = distal concentration using three-lumen tube.) within- nor between-individual variances are significantly different in the two groups of observations ( $P>0.2$ in every case).

Although the results obtained with the threelumen tube cannot be compared statistically, column 4 of Table I and Fig. 3 suggest that the variation of results both between and within individuals is at least as great as, if not greater than, that obtained with the two-lumen tube, even in the absence of luminal occlusion.

Individual glucose and water absorption rates in the present series are correlated in Figure 4. Since contaminating material contains little glucose, it might be expected that a combination of contamination and reflux would greatly affect the quantitative relationship between individual glucose and water absorption rates. In Fig. 4, there is no definite separation of the results obtained with and without luminal occlusion, except that the spread of results in the latter series is greater. There is a significant correlation between all these results grouped together, excluding the single bracketed point $(\mathrm{r}=+0 \cdot 758$, $P<0.01)$. With this one exception, luminal occlusion appears to make little or no difference to the correlation between glucose and water absorption rates.

\section{Discussion}

It has been possible in all these normal subjects to inflate the occluding balloon and prevent contamination of the test segment for periods of at least one hour. This may not apply to a pathological intestine, and for example, in one subject with diarrhoea and hypokalaemia (unpublished observation) maximum inflation of the balloon produced neither pain nor complete occlusion, suggesting that the gut was too flaccid to be satisfactorily occluded.

Luminal occlusion does not significantly affect any of the mean segmental absorption rate studies, although there is a tendency for individual absorption rates, especially glucose, to be reduced. Mean absorption rates without occlusion are similar to those obtained in a previous study, using the simple double-lumen tube without a balloon. This suggests that the presence of a balloon, either inflated or deflated, does not interfere with, or affect segmental absorption rates. It has always been a theoretical objection to this method that the balloon might interfere with local mucosal blood flow or motility to such an extent as to affect seriously segmental absorption rates, but this does not seem to be the case in practice. Phillips and Summerskill (1967) came to the same conclusion on the basis of very indirect evidence.

Effective luminal occlusion should prevent both contamination by fasting intestinal secretions 
from above and proximal reflux of infused fluid. Therefore neither of these factors significantly affects mean absorption rates in a series of observations on normal subjects, confirming our previous observations and their interpretation (Sladen and Dawson, 1968). However, the current evidence is more direct and has the great advantage that paired observations in individuals have been made, with identical experimental conditions of flow rate and solute composition. This answers a major criticism of our earlier conclusions made by Soergel (1969).

The only statistically significant effect of luminal occlusion on individual absorption rates has been to reduce the variance of glucose and water absorption. In four individuals (Fig. 2), glucose absorption rates were strikingly reduced by luminal occlusion. Since fasting intestinal contents contain small or negligible concentrations of glucose (Whalen, Harris, Geenen, and Soergel, 1966, and personal observations), it follows that contamination will not seriously affect glucose absorption rates. However, reflux will increase absorption rates by an amount related to the increase in surface area exposed to absorption. This may be the explanation for the effect of luminal occlusion in these four individuals and, if so, the ratio of absorption rates should give an estimate of the extent of reflux. These ratios are in fact $1.84,1 \cdot 71,1.53$, and 1.35 , suggesting that reflux may occur over a length of $25 \mathrm{~cm}, 21 \mathrm{~cm}, 16 \mathrm{~cm}$, and $10 \mathrm{~cm}$ respectively. On this basis, the ratio of 1.26 of mean absorption rates of glucose suggests that reflux may occur over a mean length of $7-8 \mathrm{~cm}$. This is a very much smaller estimate than that obtained by Fordtran (1969) on the basis of extremely indirect evidence. This evidence related to rates of disappearance of isotropic tracers from adjacent jejunal segments of different lengths and with probably different but unspecified luminal flow rates. Nevertheless, the important conclusion is that whereas reflux may vary considerably from subject to subject,

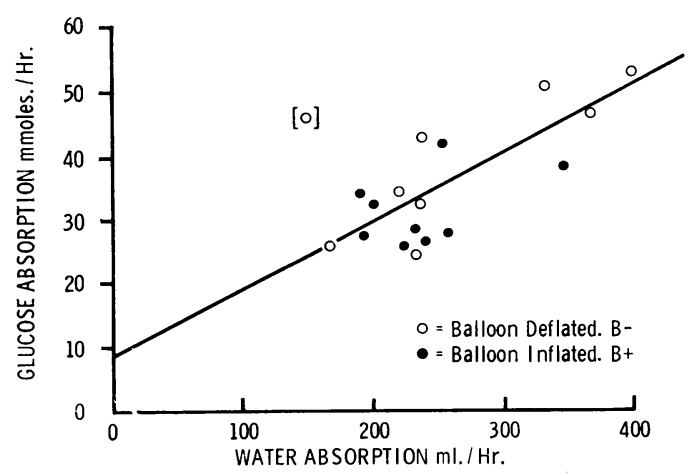

Fig. 4 Correlation between individual glucose and water absorption rates obtained in the present study. The line is the calculated regression line obtained by the method of least squares excluding the single bracketed observation. it has not affected the mean glucose absorption rate to a significant extent in this study.

Such reflux in individual subjects should affect water and electrolyte absorption rates to a similar extent. However, contamination by fasting $\stackrel{\mathcal{F}}{\stackrel{乛}{+}}$ intestinal contents, consisting predominantly of $\bar{C}$ water and $\mathrm{NaCl}$, will reduce this effect. A combination of reflux and contamination should therefore greatly affect any correlation between individual glucose and water absorption rates. के Figure 4 shows that this correlation is not in fact $\vec{\circ}$ materially affected by luminal occlusion in this study, with one exception. Indeed, of the four $\vec{\omega}$ subjects discussed in the previous paragraph who have had apparently considerable reflux, three $巳$ have a comparably high water absorption rate during the unoccluded period. In these three subjects negligible contamination can have occurred. The remaining subject had a dispro- $\$$ portionately low water absorption rate during the unoccluded period, represented by the exceptional point in Figure 4 . He seems to be the only example, in this series, where a combination of appreciable reflux and contamination has greatly affected the quantitative relationship between individual glucose and water absorption rates. From these considerations it seems reasonable to conclude that variable reflux is largely responsible for the increased variance of glucose and water absorption rates during the non-occluded perfusions.

In practice, troublesome contamination is an intermittent phenomenon and produces a marked fall in PEG concentration in individual samples. We have considered this to be the explanation if the PEG concentration in one sample is more than $20 \%$ less than the mean of the other samples. In such cases, the sample concerned has been excluded. This happened in four of 27 samples obtained during the nine perfusion periods with balloon deflated, but in only one of the 27 samples obtained during luminal occlusion, presumably because an undetected leak had occurred. In one perfusion period out of four in one individual subject gross continuous contamination was $D$ responsible for totally invalidating the results and this study was not, in fact, part of the present series of observations.

Intra-individual triplicate variations have been calculated (Fig. 3) in an attempt to assess to what $\omega$ extent contamination and reflux affect the achievement of a steady state situation. The perfusion method depends in theory on the setting up of a $\mathbb{D}$ steady state, but not all workers indicate to what extent this applies to their own studies. In this series, the median triplicate variation of PEG concentration was less than $10 \%$ of the mean and luminal occlusion significantly reduced this variation to less than $10 \%$ in all the perfusion periods. This agrees closely with the variation reported by Phillips and Summerskill (1967), using an occlusive balloon. In an earlier study Fordtran, Levitan, Bikerman, Burrows, and Ingelfinger $\stackrel{\bullet}{\rightleftharpoons}$ 
(1961) found a variability of $\pm 10 \%$ in consecutive PEG concentrations over a prolonged period but, as they infer later (Fordtran, 1966), their method did not exclude contamination completely. Probably, therefore, a combination of even small amounts of reflux and contamination will increase the variability of marker concentration in consecutive samples in many individual studies. As a consequence of this, the variation of triplicate water absorption rates has been significantly reduced by luminal occlusion.

However, the variation of triplicate glucose and sodium absorption rates within individuals was not significantly affected by inflation of the balloon. Probably, therefore, the extent of reflux does not vary appreciably during individual perfusions. The variation of glucose absorption is similar to the $10 \%$ mean variation reported by Holdsworth and Dawson (1964) using a simple double-lumen tube. No comparable reports of intra-individual variation of sodium absorption rates have appeared.

Variability of absorption rates both within and between individuals using the triple-lumen mixing segment method has also been assessed. As already stressed, these findings can be compared only approximately with those obtained using the two-lumen method, because inflow rates and solute concentrations of fluid entering the study segment are dissimilar. However, in these studies (Table I, column 4, and Fig. 4) the variability of absorption rates both between and within individuals is as great as or greater than the variability obtained with the two-lumen method, even in the absence of luminal occlusion. Although the mixing segment can theoretically overcome the problems of contamination and reflux, it introduces other sources of variability of results. Absorption of solute and fluid by the mixing segment produces a variable inflow rate and solute composition of fluid entering the study segment and both these factors may affect segmental absorption rates (Sladen and Dawson, 1969a). Furthermore, the efficiency of mixing may be variable (Whalen et al, 1966). These authors recommend a 'staggering' method of calculating absorption rates, which they claim reduces errors due to inefficient mixing of luminal contents. We have adopted this method in calculating the results but the variability is appreciable in spite of this. The studies of Whalen et al (1966) suggest that this variability could be reduced appreciably by prolonging the collection time from 30 to 60 minutes.

It may be concluded that, using the doublelumen perfusion method, variable reflux of infused fluid and contamination by fasting intestinal contents both contribute to the variability of water and solute absorption rates in individual studies. Therefore, in studies on individual subjects or small groups of subjects it would seem advisable to reduce these factors as much as possible. The occlusive balloon method is effective in this respect, but has two main practical disadvantages. It is essential to be certain that there is adequate luminal occlusion during the study and this requires frequent injections of another marker capable of detecting leakage at the bedside. Occasionally some individuals find the balloon so distressing that effective occlusion is impossible. This occurred in one subject, who was excluded from the series. However, if it is necessary to control flow rate and solute concentration, as in kinetic studies of absorption, then this method would be very suitable. The triple-lumen tube method is simpler to manage, but in these studies produced rather more variable absorption rates. However, a statistical comparison of the accuracy of the two methods cannot be made from the present results. The large variability which exists and the slight changes in overall absorption rates seen when the effects of contamination and reflux have been obviated must mean that other, as yet uncontrollable factors, are of more importance as a source of error with this type of technique.

\section{Addendum}

As this paper was being prepared for publication a comment has appeared (Modigliani and Bernier, 1969), which briefly describes rather similar experiments with a proximal occlusive balloon. Their results appear to be very similar to our own in suggesting that variable reflux is a more important source of error in individual studies than contamination ('pollution').

This work has been supported by a grant from the Wellcome Trust, during the tenure of a senior research fellowship in clinical science, and also by the Board of Governors of St Bartholomew's Hospital.

We should like to thank Mr R. Shields for advice about the construction of the tubes, Miss N. Humphreys for statistical advice, and Miss E. Head for secretarial help.

\section{References}

Cooper, H., Levitan, R., Fordtran, J. S., and Ingelfinger, F. J. (1966). A method for studying absorption of water and solute from the human small intestine. Gastroenterology, 50, 1-7.

Fordtran, J. S. (1966). Marker perfusion techniques for measuring intestinal absorption in man. Gastroenterology, 51, 1089-1093.

Fordtran, J. S. (1969). Segmental perfusion techniques. Gastroenterology, 56, 987-989.

Fordtran, J. S., Levitan, R., Bikerman, V., Burrows, B. A., and Ingelfinger, F. J. (1961). The kinetics of water absorption in the human intestine. Trans. Ass. Amer. Phycns., 74, 195-206. 
Holdsworth, C. D., and Dawson, A. M. (1964). The absorption of monosaccharides in man. Clin. Sci., 27, 371-379.

Huggett, A. St. G., and Nixon, D. A. (1957). Enzymic determination of blood glucose. Biochem. J., 66, 12 P.

Hyden, S. (1955). A turbidometric method for the determination of the higher polyethylene glycols in biological materials. K. Lantbr. Högsk. Annlr., 22, 139-145.

Modigliani, R., and Bernier, J. J. (1969). Perfusion techniques in the study of absorption in man. Gut, 10, 1041.

Phillips, S. F., and Summerskill, W. H. J. (1966). Occlusion of the jejunum for intestinal perfusion in man. Mayo clin. Proc., 41, 224-231.

Phillips, S. F., and Summerskill, W. H. J. (1967). Water and electrolyte transport during maintenance of isotonicity in human jejunum and ileum. J. Lab. clin. Med., 70, 686-698.

Sladen, G. E. (1969). Perfusion studies in relation to intestinal absorption. Gut, 9, 624-628.

Sladen, G. E., and Dawson, A. M. (1968). An evaluation of per- fusion techniques in the study of water and electrolyte $\Omega$ absorption in man: the problem of endogenous secretions. Gut, 9, 530-535.

Sladen, G. E., and Dawson, A. M. (1969a). Effects of flow rate on the absorption of glucose in a steady state perfusion $\stackrel{\oplus}{\longrightarrow}$ system in man. Clin. Sci., 36, 133-145.

Sladen, G. E., and Dawson, A. M. (1969b). Interrelationships between the absorption of glucose, sodium and water by the normal human jejunum. Clin. Sci., 36, 119-132.

Snedecor, G. W., and Cochran, W. G. (1967). Statistical Methods, 6th ed., chapter 10. Iowa State University Press, Iowa.

Soergel, K. H. (1969). An evaluation of perfusion techniques in the study of water and electrolyte absorption in man: the $\mathrm{C}$ problem of endogenous secretions. Gut, 10, 601 .

Whalen, G. E., Harris, J. A., Geenen, J. E., and Soergel, K. H. (1966). Sodium and water absorption from the human small intestine. The accuracy of the perfusion method. $\vec{\omega}$ Gastroenterology, 51, 975-984.

\section{The October 1970 Issue}

\section{THE OCTOBER 1970 ISSUE CONTAINS THE FOLLOWING PAPERS}

An interplay of genetic and environmental factors in familial hepatitis and myasthenia gravis SENGA WHITTINGHAM, IAN R. MACKAY, AND Z. S. KISS

A case of the Dubin-Johnson syndrome complicated by acute hepatitis RAJIV R. VARMA, JOHN M. GRAINGER, AND PETER J. SCHEUER

Idiopathic acute fatty liver of pregnancy $\mathrm{K}$. J. BREEN, K. W. PERKINS, S. P. MISTILIS, AND R. SHEARMAN

Dose response relationships of insulin hypoglycaemia and gastric acid in man J. H. BARON

A case of the Zollinger-Ellison syndrome associated with hyperplasia of salivary and Brunner's glands B. S. JONES, J. J. O'HAGAN, D. N. PHEAR, AND E. SHEVILLE

Recurrent acute retrograde intragastric intussusception J. ALEXANDER WILLIAMS AND J. F. FIELDING

Pepsin secretion in man after Histalog stimulation MICHAEL D. TURNER, PAULA J. MAYER, LEON L. MILLER, AND HARRY L. SEGAL
The role of chronic blood loss in the pathogenesis of postgastrectomy iron-deficiency anaemia J. M. HOLT, M. W. L. GEAR, AND G. T. WARNER

Histological localization of plasminogen activator and proteolytic activity in the human stomach and duodenum P. ERAS, P. HAR PEL, AND S. J. WINAWER

Oestrus and gastric secretion in the dog JOHN H. LANDOR AND ROBERT A. WILD

The interrelationships of pancreatic enzymes in human duodenal aspirate D. M. GOLDBERG AND K. G. WORMSLEY

Electrical potentials of the sigmoid colon and rectum in irritable bowel syndrome and ulcerative colitis c. J. EDMONDS

Gastric leiomyoblastoma B. BOSE AND J. CANDY The selective nerve stain leucomethylene blue as an intraoperative aid to achieving complete vagotomy M. L. FRIMER, M. M. COHEN, R. C. HARRISON, AND I. B. HOLUBITSKY

Progress report Inhibition of gastrointestinal secretion K. G. WORMSLEY

Notes and activities

Copies are still available and may be obtained from the PUBLISHING MANAGER, BRITISH MEDICAL ASSOCIATION, TAVISTOCK SQUARE, LONDON WC1H 9JR price 17s. 6D. 